\title{
Introduction to the Contemporary Ideological and Political Education in Colleges and Universities
}

\author{
Jiangping Liu
}

Fire Academy of Public Security Department, Kunming 650208, China.

\begin{abstract}
The ideological and political education is the basic means that ideological and political education workers use for educatees. It is a bridge that links theory and practice of education. Only the ways to use are proper and reasonable will ideological and political education in colleges and universities get twice the results with half the efforts. At present, the ideological and political education in colleges and universities mainly proceeds through classroom teaching, campus activities, social practice and so on, forming three-dimensional education system with family and society. It educates the student with scientific cultures, moral characters, aesthetic sentiment and other aspects of education directly or indirectly. Ideological and political education ways is the important aspect of ideological and political education, and also is the important topic that each education worker should research. Educators in colleges and universities should innovate education ways constantly and build democratic and harmonious education atmosphere for educatees.
\end{abstract}

Keywords: Colleges and universities; the ideological and political education; education ways.

\section{浅谈消防院校思想政治教育途径 一以公安消防部队高等专科学校为例}

\author{
刘江萍
}

公安消防部队高等专科学校, 昆明 中国

摘 要: 高校思想政治教育途径就是思想政治教育工作者对受教育者进行教育的基本手段, 是 教育理论与实践联系的桥梁, 只有途径运用得恰当且合理, 高校思想政治教育才会取得事半 功倍的效果。目前公安消防部队高等专科学校进行思想政治教育主要通过课堂教学、校园活 动、社会实践等途径, 与家庭、社会形成三维教育体系, 或直接或间接的对学生进行科学文 化、道德品质、审美情操等方面的教育。军校思想政治教育途径是思想政治教育的重要方面, 也是每一个部队教育工作者应研究的重要课题。

关键词：高校；思想政治教育；途径

\section{1. 高校思想政治教育途径概述}

高校思想政治教育主要针对在校大学生和研究生, 是高校为了实现其教育目标和教学任 务, 用社会主流的思想意识、价值观念和道德规范对受教育者实施有目的、有计划、有组织 的教育影响，使受教育者成为社会所需要的人且对社会有一定认同感的教育实践活动。

思想政治教育的途径是指为了达到一定的思想政治教育目的，使思想政治教育内容得以 顺利开展所采用的主要方式, 高校思想政治教育途径是使受教育者能更好地接受世界观、人 生观、价值观教育并付诸于行动所采用的符合高校特色和学生特点的方式方法。正如毛泽东 曾形象的说: “我们的任务是过河, 但是没有桥或没有船就不能过。不解决船或桥的问题, 过河就是一句空话。不解决方法问题, 任务也只是瞎说一顿。” [1] 正确的思想政治教育方法 是实现和完成高校教育目标的前提条件, 也是使学生养成良好习惯、健康成长的有力保证。 
目前，公安消防部队高等专科学校的思想政治教育工作者主要包括政治部、各学员大队 的德育工作者、思想政治理论课的专业教师、学员干部等, 他们组成了思想政治教育网络, 共同营造出适合学员成长的教育环境。

\section{2. 消防院校的思想政治教育的主要途径}

2.1. 重视课堂教学, 采用灌输式教育

所谓思想政治教育的灌输就是教育者正面地、直接地、有计划地对受教育者进行教育, 使之形成坚定的理想信念，从而提高受教育者的思想政治素质。理论灌输是我党一直坚持的 教育途径, 如今, 面对瞬息万变的世界和西方思想的浸入, 中国化马克思主义必须得到中国 公民尤其是国家主力军一一大学生的广泛认同。我国的高校都有专门的政治公选课, 各个学 校都开设了《马克思主义基本原理》 《毛泽东思想和中国特色社会主义理论体系概论》《中 国近现代史纲要》《思想道德修养及法律基础》 [2] 以及《形式与政策》等课程, 公安消防部 队高等专科学校主要开设了《马克思主义基本原理》 《毛泽东思想和中国特色社会主义理论 体系概论》 《中国近现代史纲要》和《》, 政治理论课老师通过统一的教材与课程系统地向 学员灌输马克思主义的人生观与价值观, 引导学员坚持中国特色社会主义理论体系的主流意 识形态。

2. 2. 注重通过校园活动或社会实践来提高思想政治教育的效果

思想政治教育是一种实践活动，各高校为了弥补思想政治教育课堂教程的不足，在采用 思想政治理论课课堂教学这一主渠道的同时, 也增加了学生参与课外活动和走进社会的机会, 以此增强思想政治教育的影响, 进而提高思想政治教育效果。公安消防部队高等专科学校也 是如此。各种校级、班级教育活动是效果比较明显的一种教育途径, 例如: 时事政策讲坛、 庆国庆主题晚会、观看爱国主义影片以及其它参观访问活动、主题班组会等。同时进行多种 形式的义务服务, 如爱心募捐、公益宣传、为老年人和残疾人服务等, 这增加了学员对社会 现实的了解, 加深了对劳动意义和人生价值的认识, 培养了社会责任感。学校运动会或其他 体育比赛也已成为学校培养学员心理素质的最好形式, 比赛中所体现的集体观念和竞争意识 是学员们仅在课堂上难以体会到的。

2. 3. 利用传播媒介做好思想政治教育工作

我国非常重视社会與论的导向作用，书籍、报刊、电视、广播、网络都是我们生活中常 见的传播工具。军校也如此, 面对求知欲强烈、接收新事物较快的学员, 学校大力发挥校园 媒介的重要作用, 以学员喜闻乐见的形式呈现出融思想性、知识性和趣味性于一体的传播内 容，使学员在学习科学文化知识的同时了解社会时事热点、接受思想政治教育。同时，开设 公安消防部队高等专科学校微信公共号、校园广播电视台、校园主页等积极传播校园文化和 社会先进文化的主流方向。

借助于多媒体, 典型教育也成为传递社会主流意识形态、提高学员思想觉悟的重要途径。 典型教育是通过生活中典型的人或事进行教育，引发受教育者思想情感的共鸣，引导人们向 更优秀的人学习, 较单纯的说理更有感染性和可接受性。新时期的典型教育应与新媒体结合 起来, 例如组织学员观看 “感动中国年度人物”、历史人物故事等或邀请优秀校友座谈, 充 分发挥先锋模范的带头作用。

2.4. 重视院校党团建工作

组织建设是思想政治教育的主要途径之一，通过党团活动开展思想政治教育是我国的一 直以来的优势和特点。[3] 在军校中也一样, 围绕学校党政中心工作, 党内可以开展 “优秀团 干部”、“优秀党员”、“先进青年” 评选等各种丰富的党团建设活动，每个学员大队也可 积极开展党团校或沙龙活动, 围绕当前的社会热点进行讨论, 及时了解学员的思想动态, 把 不良思想苗条扼杀在摇篮中。通过这些党团建工作的开展, 充分发挥其政治导向、组织领导 作用以及党员的模范示范带头作用, 把更多优秀的年轻人吸收到党组织中。党团建工作充分 
发挥了它在对学生进行思想政治教育方面的优势, 将思想政治教育融入到与党员、团员息息 相关的各类活动中, 严格要求他们, 积极培育可靠的社会主义接班人。

\section{3. 对当代消防院校思想政治教育途径的反思}

\section{1. 消防院校侧重于显性教育途径}

我国对学生进行思想政治教育最主要的途径就是专门的教育者通过政治公共课或借助于 党团组织来进行的, 用比较直接的方式把观点或要求明确地告诉受教育者, 体现了鲜明的政 治性、计划性。显性教育的见效是比较快的，消防院校也不例外。但根据思想政治教育及大 学生的特点, 我国高校应更注重显性教育和隐性教育两种教育途径相结合, 在所有的课程中 都渗透德育的内容而不仅仅在公共政治课上，重视隐蔽课程的效果。同时注意思想政治教育 的实施路径从过去的单一化向多样化过渡，拓宽思想政治教育的维度，积极采用如主题讨论、 参观访问、调查研究、志愿服务等以学员为主体的活动, 充分调动学员参与的积极性, 强调 榜样示范的作用, 潜移默化地灌输思想政治教育内容, 将社会的要求传输给受教育者, 延伸 思想政治理论课的课堂教学效应, 注重在实践活动中塑造学员的健康人格。

\section{2. 消防院校更注重教育者的引导作用}

中国在数千年的发展中始终强调国家集体利益高于个人利益，这种观念反映在思想政治 教育途径上就是重视教育者而轻教育对象, 强调师道尊严, 而不太注重教育对象的主体作用, 但是随着社会民主的发展和个性的解放, 教育者应更注重学生自主性的发展, 重视受教育者 的自省内求, 也就是说留给受教育者更多的反思空间, 锻炼其自我监督和自我管理能力, 让 其检查自身的德行，追求更高的道德水平，其实这也是我国传统的思想政治教育途径之一。 儒家从人性善的观点出发, 认为反省内求是完善人格、达到圣人的途径, 因此, 儒家十分强 调 “克己”、“内讼”、“正心”、“诚意”, 强调对自己道德品质的严格要求; 孔子的学 生曾参也提出 “吾日三省吾身” 的主张; 孟子进一步提出 “反求诸己” , 这是对孔子 “内省” 思想的继承和发展。[4]

我国古今的教育思想都表明，只有使教育标准、行为规范内化为个人的内在需求，产生 内在驱动力, 思想政治教育目标才能真正有效地实现, 而内驱力的产生和强化过程就是内省 与自求的过程。因此教育者的引导作用与受教育者的自省内求相结合在强调学生个性发展的 当代消防院校中有更深远的意义。

\section{3. 消防院校的心理咨询机构尚不完善}

我国心理咨询机构的发展才刚刚经历了十多年，大部分高校才陆续开展心理咨询工作， 很多高校对心理咨询的要求不是很高, 并且从事该行业的教师的专业化程度也不是很高, 因 此, 我国高校的心理咨询工作大多还只是流于形式, 公安消防部队高等专科学校也时如此。 但随着社会竞争的激烈和人们压力的增大，有越来越多的人或多或少的存在些心理问题或焦 虑, 所以军校更应重视对学生的心理咨询这方面的工作, 将心理健康教育纳入到学校的思想 政治教育体系中, 通过开设大学生心理健康教育的必修或选修课程、专题报告、开通心理咨 询热线, 开展团体心理训练活动等途径来提高学员的自我认识和自我评价能力, 解决学员日 常生活中遇到的困惑和各种棘手的问题, 促进学员不断成熟, 增强学员的自信心和解决问题 的能力, 切实把对学员的心理健康教育工作落到实处。加大对心理咨询机构建设的资金投入, 建设一支以专职教师为主, 专兼结合、素质较高的心理健康教育与咨询队伍, [5]为学员的身 心健康和健全人格发展提供保障。

3. 4. 消防院校应更重视学校思想政治教育与家庭、社会的合作

毛泽东说过：“思想政治工作，各个部门都要负责，共产党应该管，青年团应该管，政府 主管部门应该管，学校的校长教师更应该管。”[6-8]这就是说，学校的思想政治教育工作不 能只靠少数思想政治教育工作者完成, 这应是全校乃至全社会的事情, 是每一个人的事情, 因为学员的茁壮成长关乎着祖国的未来。家长是首先对子女进行各方面的教育的人, 当然包 括道德品质、生活态度的教育, 家长的一言一行都会对子女产生深远的影响, 家庭氛围也影 
响着子女的个性发展; 学校是有目的、有计划的对学员进行教育的专门场所; 社会大环境对 公民的世界观、人生观和价值观的形成和确立更是起着至关重要的作用。所以，社会的各个 部门和组织应共同形成一个目标一致、相互作用、协调发展的综合教育网络, 发挥教育合力 的作用，以促使思想政治教育效果的最优化。

消防院校的思想政治教育同家庭教育的合作可通过家长学校、学校同家长的通讯往来等 方式加强学校同家长的联系, 向家长介绍学生的在校表现, 征求家长对学校德育工作的配合 或意见, 让家长也充分参与到学校德育工作中来，共商思想政治教育大计。同时，应充分发 挥社会公共环境资源的思想教化作用, 院校或家长可通过带领学生参观各种各样的博物馆、 历史遗迹、名人故居或参加素质扩展训练等增强学员的民族自豪感和综合素质, 适时引导学 员树立远大抱负。

\section{参考文献}

[1] 李洋. 浅析中美两国学校思想政治教育实施方法的异同 [D]. 东北财经大学， 2007

[2] 阎桂祥，徐秉琦. 坚持 “三性” 原则实现 “两课” 教育教学与时俱进 $[\mathrm{J}]$. 教育理论与实 践，2003(03)

[3] 唐瑛. “与时俱进” 与高校学生思想政治教育 $[\mathrm{J}]$. 西南民族大学学报 (人文社科版)，2003 (07)

[4] 唐莉. 我国思想政治教育的特点及启示 $[J]$ 。南京理工大学学报，2009(02)：91

[5] 李合亮. 思想政治教育探本 $[M]$. 北京：人民出版社， 2007

[6] 毛泽东. 关于正确处理人民内部矛盾的问题 [M]. 北京: 中共中央党校出版社, 2008

[7] 王熠华.当代中美两国高校思想政治教育方法比较 [D].西北师范大学，2010

[8］王长存. 思想政治建设百题释疑 [M] . 北京：国防大学出版社，2004.

[9] 林斯坦. 论现代德育的策略---隐蔽德育意图 [J]. 教育评论，2001（5） 